\title{
EDUCACIÓN, CONTEXTO Y GÉNERO: UN RECORRIDO HASTA LA TRANSICIÓN ${ }^{1}$
}

\author{
Carmen Mañas Viejo \\ carmen.mavi@ua.es \\ Universidad de Alicante
}

Recibido: 28-02-2013

Aceptado: 18-03-2013

\section{Resumen}

Con el objetivo de estudiar y comprender desde una perspectiva de género el recorrido y discurso histórico de un ámbito como la educación, nos aproximarnos a las claves que determinan su campo de actuación, durante un periodo intenso y corto: la Transición política española. Nos interesamos en este artículo por el ordenamiento educativo y por los movimientos pedagógicos. Utilizaremos fuentes primarias y secundarias, así como historias de vida. Y esperamos contribuir a construir un imaginario cultural femenino de referencia.

Palabras Clave: España, Transición, ordenamiento educativo, movimientos pedagógicos, impacto de género

\begin{abstract}
With the purpose of understanding and analyzing, from a gender perspective, the historical discourse construction of an area such as education, we approach to the key factors that determine its field of action during a brief but intense period: the Spanish political Transition. In this paper, we focus on the Educational System regulation and the pedagogical movements. To this end, we will use primary and secondary sources and real-life stories. We hope to contribute to the construction of a female culturalimaginary baseline.
\end{abstract}

Keywords: Spain, Transition, Educational System regulation, pedagogical movements, gender impact.

\footnotetext{
${ }^{1}$ Este estudio ha sido realizado en el marco del Proyecto de investigación 'Haciendo Historia: Género y Transición en España', financiado por el MICINN (Ref. FEM2010-19068).
} 


\section{Introducción}

La educación de un país no cambia a golpe de ley, pero las leyes marcan el acceso y el recorrido educativo a seguir en cada momento, y dan cuenta del pulso y tensión vital del momento en que se crean y se derogan. Como primera aproximación a la educación durante el periodo denominado Transición política española, nos proponemos estudiar, con perspectiva de género, las leyes que configuraron el mapa educativo de España hasta ese periodo ${ }^{2}$. Consideramos que el objetivo de las leyes educativas a las que nos referimos, así como las personas a quienes afectan, varones y mujeres, hacen pertinente el estudio del impacto en función del género ${ }^{3}$. Nuestro objetivo fundamental es contribuir al conocimiento, difusión y visibilización de la posición de las mujeres en la educación y de su contribución, para influir en la construcción de un imaginario cultural que integre el valor de lo femenino y a las mujeres en su representación cotidiana.

Para comprender el mapa educativo español de este periodo es imprescindible realizar una mirada retrospectiva (Subirats, 1994) ${ }^{4}$, aunque sea someramente ${ }^{5}$, que nos ayude a situarnos y comprender mejor el agridulce discurso coeducativo que, podríamos decir, de alguna manera definió, en el terreno educativo, el período de la transición española.

Nos situamos en el siglo XIX, las guerras napoleónicas inician un periodo liberal que culmina en la constitución de $1812^{6}$ e introduce ideas muy renovadoras en el ámbito educativo, como son la universalidad e uniformidad de la enseñanza primaria en todo el Estado Español. Y consigue algo fundamental, arraiga en la sociedad española la idea de que la educación es

\footnotetext{
${ }^{2}$ Andrés Sáenz Del Castillo (1999), nos recuerda que el periodo de la Transición tiene tratamientos diversos, incluso en la determinación de su inicio; Victoria Prego propone la muerte del general Carrero Blanco (23 de diciembre de 1973); otros los más, proponen el 20 de noviembre de 1975, (muerte de Franco). El momento en que se considera terminada la Transición, también admite diversidad de fechas: la proclamación de la Constitución (1978); el golpe de Tejero (1981); la victoria electoral del PSOE (1982) o el tratado de Maastricht (1993). En nuestra investigación delimitamos este periodo entre 1975 y 1982, pero tratamos de no obviar sus antecedentes y estudiar sus consecuencias.

${ }^{3}$ Jornadas Internacionales 8,9 y 10 octubre de 2003 (Junta de Andalucía, 2003). Guía para la evaluación del impacto en función del género. El 30 de octubre de 2003, el gobierno español, siguiendo la comunicación de la Unión Europea sobre la conveniencia de analizar de manera transversal (mainstreaming) el impacto de género en el conjunto de las políticas, mejorando su calidad y eficacia.

${ }^{4}$ La historia del acceso de las mujeres a la educación está muy ligada a las reivindicaciones de estas. Un punto de inflexión a nivel internacional lo constituye el manifiesto feminista "Avinduication of the rights of Woman (La vindicación de los derechos de la Mujer) realizado por Mary Wollstonecraft en La 1792 En él se manifiesta que la supuesta irracionalidad de la mujer, no es una idiosincrasia de su naturaleza, sino la consecuencia lógica de una falta de educación secular. El rechazo a las ideas que preconiza la "Educación de Sofia", liderado, fundamentalmente por mujeres pertenecientes a las clases altas de la sociedad, será utilizado en el siglo XIX como argumento para fomentar la educación de todas las mujeres. Cómo sabemos en España, el derecho a voto de las mujeres, no se conseguirá, y de manera muy efímera hasta el 1 de diciembre de 1931.

${ }^{5}$ Nos guiamos en este recorrido somero en "Evolución del sistema educativo español" elaborado por el Ministerio de Educación Cultura y Deporte (2004). El sistema educativo español. Madrid: MECD/CIDE

${ }^{6}$ Qué dedica su título IX en exclusiva a la instrucción pública.
} 
competencia del estado y no del gobierno. El objetivo de desarrollar estos principios básicos, que otorgaba la constitución de 1812 a la población española, culmina con el informe que Manuel José Quintana (1946) ${ }^{7}$ público en 1814. Las ideas introducidas por el informe quintana de 1814, defendiendo la instrucción como igual, universal, uniforme, pública y libre van calando, y en 1821, en el Reglamento general de la Instrucción pública, aparece la necesidad de instruir, de manera básica, a las mujeres. Esta necesidad la determina la sociedad industrial que comienza y necesita mano de obra, y no renuncia a ninguna mano, tampoco a las manos de mujer. Para la instrucción de las mujeres y de las personas con diversidad funcional sensorial (cojos y cojas, ciegos y ciegas sordos y sordas...todas) es un hito, un cambio importante de mentalidad en la sociedad. El reglamento se ocupa por primera vez de la necesidad de enseñar a las niñas no solo a leer y a escribir, también a contar, sin duda algo útil para la compraAunque el propio reglamento indique la necesidad de que esta instrucción la reciban ellas y ellos en espacios diferentes, ya que lo varones podrían distraerse...- No, nos hagamos ilusiones, en el informe Quintana, el perfil de maestra que se requiere es, como define San Román Gago "la maestra analfabeta".

"A la maestra analfabeta (primer modelo de maestra de escuela pública, que supone la primera fase de incorporación de la maestra a la escuela pública de niñas, y se produce vía exclusión de la educación de los niños) se le encomendó la tarea de reproducir ese ideal de cultura femenina que aseguraba la educación hogareña de las niñas de las clases más desfavorecidas" (Gago, 1998: $111)$.

Las ideas filosóficas imperantes en la teoría pedagógica fueron las ideas de Rousseau (1973), Kant, Montesino (Pellecin, 1987), Fröbel y Condorcet (Puleo, 1993), entre otros, quienes representando a la ilustración, decidieron dejar fuera de ella a las mujeres. En general, opinan que su estado natural es la dependencia y su característica más sobresaliente la debilidad. Serán aptas para la educación infantil de varones, es decir, para cuidar en la escuela, espacio público, a los niños y niñas de otras que han de trabajar

En 1823, la reacción absolutista llega con la derogación del Reglamento General de Instrucción Pública de 1821 y la posterior promulgación del Plan literario de estudios y arreglo general de las universidades del Reino (1824), del Plan y Reglamento de escuelas de primeras letras del Reino (1825), y del Reglamento general de las escuelas de latinidad y colegios de humanidades $^{8}$. La consecuencia más importante de esta vuelta atrás, en materia de instrucción, pese a sus bonitos nombres, es que la educación volvía a ser competencia de la Iglesia, no del estado (Ruiz Berrio 1970:30) -a las niñas se les enseñaría a leer en los catecismos.- y quedaba exhaustivamente reglamentada y jerarquizada. Lo que si dejaba claro el reglamento de escuelas primarias, era la diferente instrucción, función y sueldo de los maestros y maestras; éstas, naturalmente, sustancialmente inferior en todo.

\footnotetext{
${ }^{7}$ el Informe para proponer los medios de proceder al arreglo de los diversos ramos de instrucción pública (llamado Informe Quintana).

${ }^{8}$ Todas ellas conocidas como el Plan de Calomadre.
} 
La regencia de $\mathrm{M}^{\mathrm{a}}$ Cristina, en 1833 , da inicio a lo que se conoce como la "década liberal" en la que los liberales progresistas y los liberales moderados, se alternan en el gobierno "sin solución de continuidad" e imponen unos y otros, durante cortos espacios de tiempo, sus ideas. Comienzan los progresistas con la desamortización, supresión de señoríos y órdenes religiosas, secularización de la enseñanza... y en 1836 se aprueba el Plan General de Instrucción Pública (Plan del duque de Rivas) ${ }^{9}$, que apenas tuvo vigencia, debido de nuevo, a los vaivenes políticos, tan definitorios de España, en el ámbito educativo. Pero, a pesar de su escasa vigencia, supuso un importante antecedente de la Ley Moyano de 1857.

En 1843, con la mayoría de edad de Isabel II, se abre un nuevo período en la historia de España que dura hasta 1854: es la llamada «década moderada». La ley clave dentro del ámbito educativo, de esta etapa, es el conocido como Plan Pidal ${ }^{10}$ del que cabe destacar que renuncia a la gratuidad e universalidad de la enseñanza en todos sus grados y establece las bases de lo que se considera como la primera definición del sistema educativo moderno español. Las escuelas de Párvulos comienzan a aparecer en España y el perfil de maestra ahora es maternal. Kant, triunfa sobre Rousseau (Gago, 1998), lo femenino es necesario para refinar la sociedad. Pero la escasez de recursos dedicados secularmente a la Educación en España hace inviable la mayoría de las propuestas y planes de ordenación de la instrucción, fundamentalmente en el medio rural, donde comienzan su andadura las conocidas escuelas unitarias (Groves, 2011). (Espacios físicos compartidos por niños y niñas de diferentes edades y en los que los maestros, ayudados por sus esposas, mujeres... maestras... atienden la diversidad curricular y cultural. Esta situación es percibida por el gobierno español como una trasgresión y en 1857 la ley de instrucción pública, más conocida como Ley Moyano ${ }^{11}$, explicita la obligatoriedad de mantener separados a los niños y las niñas físicamente en las escuelas, públicas y privadas, incluidas las escuelas rurales $^{12}$ y determina que su separación se priorice, aún en el caso de que el número de

\footnotetext{
${ }^{9}$ Este Plan reguló los tres grados de enseñanza: la instrucción primaria, que comprende la primaria elemental y la superior, la instrucción secundaria, dividida en elemental y superior, y la instrucción superior, a las que corresponden las facultades, las escuelas especiales y los estudios de erudición, respectivamente. Tras la aprobación de la Constitución de 1837 hubo intentos de desarrollar normativamente los preceptos constitucionales pero la sublevación de Espartero, imposibilitó su actuación.

${ }^{10}$ Que tratará de desarrollar los preceptos de la constitución de 1845.

${ }^{11}$ Basada en el famosos informa quintana, que comienza su andadura en 1913 y se hace público en 1914

${ }^{12}$ La ley de Instrucción pública dice, en su sección segunda, título primero: de los establecimientos públicos en su Art. 100. "En todo pueblo de 500 almas habrá necesariamente una Escuela pública elemental de niños, y otra, aunque sea incompleta, de niñas. Las incompletas de niños sólo se consentirán en pueblos de menor vecindario.

Art. 101. En los pueblos que lleguen a 2.000 almas habrá dos Escuelas completas de niños y otras dos de niñas. En los que tengan 4.000 almas habrá tres; y así sucesivamente, aumentándose una Escuela de cada sexo por cada 2.000 habitantes, y contándose en este número las Escuelas privadas; pero la tercera parte, a lo menos, será siempre de Escuelas públicas.

Art. 102. Los pueblos que no lleguen a 500 habitantes deberán reunirse a otros inmediatos para formar juntos un distrito donde se establezca Escuela elemental completa, siempre que la naturaleza del terreno permita a los niños concurrir a ella cómodamente; en otro caso cada pueblo establecerá una Escuela incompleta, y si aún esto no fuera posible, la tendrá por temporada” (España, 1857).
} 
niñas a escolarizar sea menor al cupo establecido para la dotación de una escuela. Sacrificando sin rubor toda eficacia y eficiencia en pro de la no distracción del varón. Además de separarlos físicamente también separa su instrucción, delimitando diferentes materias para unos y para otras $^{13}$. Para ellos las letras y los números, para ellas las letras de lo sagrado, el dibujo y la higiene doméstica, para unos y otras, aunque separados la religión.

La Ley de Instrucción Pública de 9 de septiembre de 1857, llamada Ley Moyano ${ }^{14}$ por ser Claudio Moyano Ministro de Fomento en el momento de su aprobación, fue fruto del consenso entre progresistas y moderados liberales, y significó la consolidación definitiva del sistema educativo liberal y el comienzo de la estabilidad del desarrollo de la instrucción pública, sobre todo en el nivel legislativo y de administración, durante más de un siglo. En 1958 se crea la Escuela Normal Central de Maestras. Es importante porque quedan, por fin, las mujeres integradas en la Escuela, pero su formación y expectativas están aún muy lejos de las de los varones. El perfil de maestra comienza a cambiar, e irá en adelante en progresión. Comienza un nuevo perfil de maestra, la maestra letrada.

Y más tarde, acontecimientos como la "Gloriosa", y la proclamación de la primera República, traen a España aíres de libertad y en el ámbito educativo, se defiende la Libertad de enseñanza y la libertad de cátedra ${ }^{15}$. La crisis interna, la depresión y consiguiente baja estima, que reflejan como nadie la generación del 98, en la que vivía la sociedad española este fin de siglo, le dio a la educación un gran protagonismo. La idea fuerza que recorría el país es que otra educación era necesaria, otra escuela era posible.

\footnotetext{
${ }^{13}$ Art. 5. En las enseñanzas elemental y superior de las niñas se omitirán los estudios de que tratan el párrafo sexto del art. $2^{\circ}$ y los párrafos primero y tercero del art. $4^{\circ}$, reemplazándose con: Primero. Labores propias del sexo. Segundo. Elementos de Dibujo aplicado a las mismas labores. Tercero. Ligeras nociones de Higiene doméstica. Véase: La Ley Moyano de 1957.

${ }^{14}$ La Ley Moyano consta de cuatro secciones. La primera, «De los estudios», regula los niveles educativos del sistema: primera enseñanza, dividida en elemental (obligatoria y gratuita para quien no pueda costearla) y superior; segunda enseñanza, que comprende seis años de estudios generales y estudios de aplicación a las profesiones industriales; y, en el nivel superior, los estudios de las facultades, las enseñanzas superiores y las enseñanzas profesionales. En la sección «De los establecimientos de enseñanza» se regulan los centros de enseñanza públicos y privados. La tercera, «Del profesorado público», regula la formación inicial, forma de acceso y cuerpos del profesorado de la enseñanza pública. Por último, en la sección «Del gobierno y administración de la instrucción pública» se establecen tres niveles de administración educativa (central, provincial y local) perfectamente jerarquizados, y se regulan unos tímidos intentos de participación de la sociedad en el asesoramiento a las diversas Administraciones. ${ }^{15}$ El 19 de septiembre de 1868 estalla la revolución conocida como «la Gloriosa», comenzando el llamado sexenio revolucionario, y en 1873 es proclamada la Primera República española. Una de las características básicas de este período en el campo de la educación es el impulso de la libertad de enseñanza. El Decreto de 21 de octubre de 1868 defendía el necesario equilibrio entre la educación pública y privada, la necesidad de unos estudios distintos en duración para personas con desiguales capacidades y la libertad de cátedra. Otro importante decreto, aprobado el 25 de octubre de ese año, organizaba la segunda enseñanza, entendiéndola como un complemento o ampliación de la Educación Primaria, que debía formar ciudadanos ilustrados dotándoles de una amplia instrucción, y regulaba las facultades de Filosofía y Letras, Ciencias, Farmacia, Derecho y Teología. Así, aunque no se produjeron grandes innovaciones en este período en materia de política educativa, muchas de las reformas introducidas en el tema de la libertad de enseñanza se incorporaron al sistema educativo español de modo definitivo.
} 
La Institución Libre de Enseñanza, en adelante ILE (1876-1938) confió en la educación como motor del cambio social y le dio prioridad; educó sus alumnos y alumnas en la libertad, el amor a la cultura y la responsabilidad y dio una importancia capital a la formación de los maestros y a la escuela pública (Benejam Arguimbau: 2002) y fue, sin duda, la mejor experiencia educativa realizada en España, pero no acabó con la controversia sobre el acceso de la mujer a la educación. Una constatación supone el planteamiento de la coeducación a todos los niveles, argumentada por Emilia pardo Bazán en el Congreso de Pedagogía de 1892 (Ayala, 2001). Esta propuesta no fue aceptada, pero evidencia que el feminismo de la igualdad había entrado en España y se hacía un hueco en la educación. La propuesta Emilia Pardo Bazán, tal y como afirma Subirats (1999), vincula la coeducación a la escuela renovada, basándose en la convivencia natural de los sexos en la familia y en la sociedad y se sustenta pedagógicamente en los mismos principios de la ILE. Otorga valor a las mujeres en sí mismas.

España entra en el siglo XX con impulso renovador, a pesar de haber sufrido, literalmente, cual péndulo, los vaivenes de gobiernos incapaces, al parecer, de pensar en el progreso de las personas a las que representan. La población. Este impulso renovador, se manifiesta, en el ámbito educativo, en la creación de interesantes movimientos pedagógicos que llevan a cabo experiencias de educación mixta, como las escuelas racionalista y laicas, la Escuela Moderna de Ferrer i Guardia, la Escuela Nueva... La institución libre de enseñanza inspiró la política educativa de la segunda república y estuvo en la base de movimientos pedagógicos tan importantes como La escuela Normal de la Generalitat (1931-1939) las propuestas de Joan Bardina (1906-1910) y los Estudis Normals de la Mancomunitat (19211923).

Las acciones encaminadas a mejorar la formación de maestros y maestras es una de las claves que revolucionan pedagógicamente las aulas en la España de finales de siglo XIX y principios del XX.

El 13 de octubre de 1923 el general Primo de Rivera encabeza un golpe militar que pone fin al periodo de la restauración. En lo que respecta al ámbito educativo, puso fin a las dudas sobre la libertad de la cátedra, está quedaba derogada. Lo más reseñable, además de esta vuelta atrás en la libertad de enseñanza, fue el permiso a universidades privadas a extender títulos públicos.

El 14 de abril de 1931 se proclama la Segunda República española y se abre una nueva etapa en el sistema educativo español. La Constitución republicana proclamaba la escuela única, la gratuidad y obligatoriedad de la enseñanza primaria, la libertad de cátedra y la laicidad de la enseñanza. Igualmente, establece que los maestros, profesores y catedráticos de la enseñanza oficial serán funcionarios. Destacan los cambios respecto a la regulación del bilingüismo, permitiendo que en las escuelas primarias se enseñe en lengua materna, aunque sea diferente del castellano; se suprime la obligatoriedad de la enseñanza religiosa; se reforma la formación inicial de los docentes; y se regula la inspección de la primera y segunda enseñanza. 
En 1933 se celebraron las segundas elecciones a Cortes de la República, dando la victoria a los partidos de la derecha. Esto supuso que se revocaran muchos de los planteamientos educativos del anterior gobierno. Los ataques principales se centraron en la coeducación, prohibiéndose a los maestros e inspectores su implantación en las escuelas primarias nacionales.

Las terceras elecciones de la República, en 1936, dieron la victoria al Frente Popular, alianza de partidos y organizaciones de izquierdas. A pesar de que entre sus promesas electorales se incluían profundas reformas educativas, el alzamiento militar, que trajo consigo la guerra civil y el final de la República, no permitió su puesta en práctica.

El 18 de julio de 1936 comienza la guerra civil española con el alzamiento militar del general Franco. Tres años más tarde, la victoria Franquista pone fin, legalmente, a la escuela mixta. El ideario político del franquismo dibujo una pedagogía basada en la obediencia, la culpa, el pecado y la aceptación de la desigualdad genética de clase social y género y la nula importancia y desconsideración a la escuela primaria (Benejam Arguimbau, 2002). La iglesia toma el poder de la educación y el estado confía la "inspección” de la educación de las mujeres a la Sección Femenina de la Falange ${ }^{16}$ (Richmond, 2012) y de nuevo los rezos, y las flores vuelven a los patios de colegios de las niñas, cuyo destino ha de estar ligado a su función biológica y al servicio social: madre y responsable del hogar. Son los años más duros de la dictadura de franquista, que en lo educativo se encuentra con un frente, las maestras (Fernández Soria y Agulló Díaz, 1999) ${ }^{17}$, contra las que ejerce una fuerte represión.

La victoria franquista vació con gran represión las escuelas de maestros y maestras sospechosos, pero no sólo vació las escuelas del profesorado, también y como no, intentó vaciar su memoria, se cerraron bibliotecas, se destruyeron libros... Benejam Arguimbau (2002:82) cuenta como en la escuela Normal, donde ella estudio, la profesora de literatura dejaba con cuentagotas algunos libros a su alumnado, siempre que este fuera discreto y dice: "Solamente quienes hayan estudiado en las escuelas normales durante los años cincuenta pueden saber el grado de penuria y humillación a la que fueron sometidas las escuelas de formación del profesorado de primaria".

A finales de los cincuenta, la autarquía franquista está agónica, no tiene recursos y necesita ayuda económica y financiera internacional, comienza el desembarco de los planes de desarrollo, que unido a los acontecimientos internacionales de los años $60^{18}$ relajaron la represión del régimen franquista. En el ámbito educativo se recoge en la Ley del bachillerato

\footnotetext{
${ }^{16}$ Que se crea en 1934 con el objetivo de servir de instrumento político al régimen franquista en la guardia y custodia de la educación femenina.

${ }_{17}$ Resaltamos las maestras, porque también fueron muy represaliadas, y es menos reconocido. Aunque naturalmente, los maestros también fueron represaliados por el régimen.

${ }^{18}$ Son innumerables y muy significativos los acontecimientos que marcaron la década de los sesenta, nos conformaremos con una pincelada que sirva de recuerdo del contexto internacional con el que España quería relacionarse. Asó señalamos, la celebración del Concilio Vaticano II, la primavera de Praga, la carrera espacial, Mao y su revolución cultural, la guerra de Vietnam, pero también los Beathls, la minifalda, las chicas en pantalón... y publicaciones como "el segundo sexo" de S. Beauvoir...
} 
de 1957, que a su vez permite aflorar escuelas privadas alternativas, auspiciadas y apoyadas por hombres y mujeres que pertenecían a ese pasado que el franquismo había querido borrar de la memoria colectiva. En esta línea hay que mencionar a la Fundación Escuela de Mestres Rosa Sensat ${ }^{19}$ dirigida por Marta i Garriga a quien se identifica con el movimiento de renovación pedagógica, cuya acción más importante estuvo centrada en la formación del profesorado, entendiendo que era la pieza clave para cambiar el sistema social establecido; estamos en 1965. Este cambio requería de la recuperación de la memoria histórica y la devolución de la dignidad a los estudios y profesión de magisterio y luchó por una escuela catalana de calidad y pública.

Se reivindica una escuela más plural, menos autoritaria, coeducación, educación sexual, formación especializada, incorporación de las nuevas teorías sobre el desarrollo, nuevos contenidos, nuevos métodos (Siguan, 1977). El término escuela pública se sitúa en el centro del discurso ${ }^{20}$. Las ideas preconizadas por la ILE, sustentan la pedagogía que se infiltra despacio, pero sin pausa en las aulas españolas (Pellecin, 1987). Tres leyes importantes, la ley sobre ordenación de la enseñanza media, llamada también Ley de Ruiz Jiménez, la ley sobre Construcciones Escolares, y por último en 1957, la ley 20 de julio de 1957 sobre Enseñanzas Técnicas todas ellas tratan de presentar un perfil menos dogmático y más atento a la calidad y que diseña el bachiller que cursaron la generación de hombres y mujeres que contribuyeron a conformar la democracia española de mediados de los 70 .

Todo este cambio social que vive el mundo occidental, y España, a su nivel, se recoge a nivel educativo, en la Ley General de Educación, de 1970 (España, 1970), que supone un profundo cambio en la estructura de la educación en España. Sin embargo esta ley no es fruto del debate y del estudio de las necesidades de nuestro país, sino de la necesidad de estar en línea con los derechos internacionales, para poder acogerse a los beneficios de intercambio comercial y ayudas de financiación exterior que los planes de desarrollo español necesitaban. La Ley General de Educación estuvo asesorada por la UNESCO y la OCEDE y financiada por el Banco Mundial, supuso un gran impacto renovador, ya que ordenó una enseñanza obligatoria, también para las nacidas mujer y gratuita en la escuela de primaria de 8 años de duración. Por primera vez la obligatoriedad de los estudios incluía a las niñas y un mismo curriculum. Se puso el foco de atención en la formación del profesorado tanto de primaria como de secundaria. El profesorado progresista vio esta ley con desconfianza ya que pretendía un cambio, sí, pero sin recuperar la memoria histórica de la educación en España, ni cuestionar los principios franquistas del nacional catolicismo en los que se inspiró. El impacto sobre el género de esta ley, fue importante, aunque no contundente, no

\footnotetext{
${ }^{19}$ Educadora Catalana, que dirigió una de las 7 escuelas normales de fue, también, impulsora de las escuelas de verano, que tomarán como ejemplo los movimientos de renovación pedagógica de gran auge a partir de 1975.Es importante subrayar su participación en importantes congresos como el I Congrés Nacional d'Ensenyament Primari a Barcelona (1909); III Congreso Internacional d'Enseignement Menager, a París (1922) y Congrés des Écoles Nouvelles, a Niça (1932).

${ }^{20}$ La Federación Nacional de MPRs presentó el documento de las cien medidas de la escuela Pública. Citado en. Andrés Sáenz del Castillo (1999).
} 
integró a las mujeres en el sistema educativo, impuso a las mujeres el sistema educativo. La LGE integra a las mujeres en el curriculum elaborado por y para los varones y las diferencias que se puedan dar entre ellos, a nivel de éxitos, fracasos y elección de futuros estudios se explican por razones biológicas naturales. Por otra parte obvian algo tan importante como el secular retraso de la incorporación de las mujeres a la educación, variable importante en cualquier estudio: los antecedentes (Castilla del Pino, 1971). Aun así esta ley era la mejor herramienta con la que avanzar. España entra en la primera ola del feminismo, en la educación, cuando Europa ya se plantea la segunda ola, el feminismo de la diferencia. Los debates en este sentido, mantenidos dentro de las instituciones educativas, son marginales, la lucha prioritaria está centrada en los recursos ${ }^{21}$.

La ley de 1970 integraba a las escuelas normales en la Universidad ${ }^{22}$. Las nuevas escuelas normales se basan en principios democráticos, donde la formación del profesorado era esencial y desde diversas asociaciones, los maestros y maestras formaban las famosas escuelas de verano ${ }^{23}$, donde ellos y ellas dedicaban parte de su periodo vacacional a formarse y compartir experiencias. Un principio femenino, se abrió paso en los movimientos pedagógicos, dedicar mi tiempo al bien común.

El mapa educativo con el que llega España a la transición presenta diversas modalidades, por un lado colegios como el Estilo de Madrid, que se sustentaba en los principios defendidos por la Institución libre de enseñanza, Una enseñanza que busca la calidad y la adecuación del curriculum a las necesidades de una sociedad que quiere desarrollar a su ciudadanía y a ella misma, donde el número de estudiantes no superase los 20 por aula, bilingüe y por supuesto mixto, es decir, un colegio coeducativo, no segregado, no masificado. Catalogado como experimental supuso un modelo para la educación que se quiso implantar en España durante la transición. También en Madrid, dirigido por Jimena Menéndez Pidal, el colegio Estilo se declaraba heredero de la Institución Libre de enseñanza, en casi todo, ya que era segregado. Estos dos tipos de modelos no se reprodujeron en las demás partes de España (Sáenz del Castillo, 1999) en las que si hubo muchos tipos de colegios religiosos segregados, casi tantos como localidades. En el norte, estaban las ikastolas, escuela pegadas a las parroquias, enseñaban vasco y otras materias y estas si serían un modelo tomado para dibujar el modelo educativo en la Transición. Pero no eran las únicas, en Galicia y Cataluña, este tipo de escuelas, de corte religioso, aunque menos arraigadas institucionalmente, también eran abundantes. La enseñanza de titularidad religiosa era tan abundante y diversa que en ella coexistían colegios avanzados en todos los aspectos, colegios avanzados y democratizantes como los de los jesuitas, y colegios nada avanzados o dedicados casi exclusivamente a catequizar y también "excesivamente rancios"

\footnotetext{
${ }^{21}$ Esto va a ser una constante en esos momentos, para muchas mujeres se les plantea la disyuntiva de no poder compatibilizar la lucha por la igualdad de géneros y la lucha por la libertad.

${ }^{22}$ La integración real, debido a las múltiples y variadas resistencias, no será hasta finales de los 90 cuando estas escuelas normales se integran realmente en las facultades de ciencias de la educación con la progresiva cualificación del profesorado que las compone.

${ }^{23}$ Inspiradas en las que comenzará a organizar a principios de siglo Rosa Sensat.
} 
como tantos y tantos colegios donde segregaban la entrada al mismo, según la clase social y posición del alumnado, sobre todo en los colegios religiosos de niñas. Pero además de los colegios religiosos y experimentales, en España confluía un sistema público de enseñanza, con su amalgama de leyes y ordenamientos...En los setenta, en el ámbito educativo confluyen el rancio franquismo y los nuevos aires de libertad. El profesorado, con gran voluntarismo, como siempre, aprovechaban la curiosidad de su alumnado para programar sesiones de lectura, visionado de películas, en ese momento los cine-forum son una actividad que casi cualquier instituto de cualquier provincia programa con películas que invitaban a la reflexión y a la crítica y al conocimiento de lo que pasaba más allá de nuestras fronteras.

En resumen, pues cuatro tipos de enseñanza, básicamente. Podemos considerar que confluyen con sus respectivas leyes y ordenamientos en la España que se prepara para la Transición: Una red heterogénea de colegios religiosos, un sistema homogéneo de colegios de primaria y secundaria públicos y algunos colegios "famosos" privados laicos y progresistas y laicos y conservadores (Sáenz del Castillo, 1999).

Las reivindicaciones con las se llega a la transición, por parte del sistema educativo se pueden resumir, en un aumento de la extensión social de la enseñanza, revisión de la pedagogía, formación y motivación del docente y aminoramiento sustancial de la farragosa burocracia que se derivaba de un sistema abusivo y desordenado de control sobre la enseñanza. Pero no son las únicas reivindicaciones, en las Jornadas Nacionales por la Liberación de la Mujer de diciembre de 1975 los grupos feministas (Robles Sanjuán, 2010) denuncian un lenguaje sexista y una cultura machista y solicitan que en la Ley General de Educación se introduzcan materias específicas femeninas, se cuestiona el androcentrismo de la ley que ha de regir la educación de hombre y mujeres y se proponen cambios en la organización del tiempo escolar, en la metodología, en la formación y en las infraestructuras (transporte escolar) .

Una vez muerto Franco en 1975, los hechos políticos en España se suceden con la velocidad que permite la política de la reforma que atempera el miedo a la ruptura.

La coronación del rey Juan Carlos I, La presidencia de Suárez en 1976, la promulgación de la Ley de la Reforma Política que aprobará el desmantelamiento de las instituciones franquistas, por las mismas instituciones franquistas y que será aprobada en referéndum por la población española; los famosos pactos de la Moncloa del 77, la legalización de los partidos políticos y organizaciones sindicales, la legalización del partido comunista... y la convocatoria a elecciones generales, del 15 de junio que dará la victoria a UCD, partido que liderara, en la figura de Adolfo Suárez, la Transición Española. En 1978 se aprueba mediante referéndum, la constitución surgida del pacto y el consenso de todas las fuerzas políticas representadas en las Cortes Españolas. La constitución está orientada a lograr mediante su ordenamiento jurídico, la libertad, la igualdad y el pluralismo político. Su artículo $27^{24}$ marca los principios generales de toda la legislación española en materia

\footnotetext{
${ }^{24}$ Aborda los derechos fundamentales y las libertades públicas.
} 
educativa. En su primer apartado garantiza el derecho a la educación de todos los españoles, y la libertad de enseñanza, que en España quiere decir garantizar la enseñanza religiosa (Agulló Díaz, 1999). Y pese a que garantiza la igualdad, en su disposición no cuela ni un acento femenino. Pero las mujeres se organizan y en 1979 proliferan las asociaciones, específicas de mujeres (Moreno, 2005; Threlfall, 2009) y las que no son específicas. Los movimientos se radicalizan y los sindicatos y los recién formados partidos políticos toman posiciones...se comienza a hablar de autogestión, de representación, de autonomía, de igualdad de clases, de elecciones sindicales, de culturas regionales específicas, de accesos a la cultura, de gratuidad... Las asociaciones de las escuelas se organizan, el tiempo ya no se "dedica" se rentabiliza; ha cambiado el valor.

La mayoría de las propuestas pedagógicas que surgen en el periodo de la transición estaban basadas en la actividad de las escuelas de verano y de allí nacerán los llamados movimientos de renovación pedagógica ${ }^{25}$. Se intentó que los maestros y maestras no tuvieran que estudiar 14 asignaturas por año; se pidió a la academia universitaria que participaran en la formación del profesorado, que unida a la formación práctica recibida en las escuelas, conformaría una excelente base intelectual y práctica al profesorado. Esta tarea fue complicada. La escuela normal de la universidad autónoma de Barcelona fue la primera en reivindicar que la entrada en el magisterio supusiese el mismo recorrido que la entrada a cualquier otra carrera universitaria, selectividad incluida, con el objetivo de ir eliminando la discriminación que representaba entrar a formar parte del magisterio español. La universidad autónoma de Barcelona dio el visto bueno en el curso 1979/80 y se aplicó al resto de universidades durante el curso 1981/82. En la misma línea la Escola normal de Cataluña siempre reivindicó que el magisterio fuese considerado una licenciatura, algo que no se consiguió hasta la puesta en marcha del plan Bolonia, como quien dice, ayer.

$\mathrm{Al}$ gobierno de UCD le toca plantearse una reforma estatal que se esperaba que fuera de largo alcance, respecto a las escuelas normales, su funcionamiento y organización y también la formación del profesorado. La división en dos departamentos del Ministerio de Educación, permitió trabajar separadamente en las reformas. Por un lado el Ministerio de Educación (ME) bajo la dirección de Otero Novas trabajaba y prácticamente ultimaba una propuesta y de otro, el MUI (Ministerio de Universidades e Investigación). Dirigido por González Seara, acordaba la creación de una comisión delegada formada por dos representantes de cada unidad para hacer propuestas concretas.

El plan otero planteaba una larga lista de cuestiones, algunas de ellas, aún hoy tendrían vigencia en su reivindicación: Desajuste entre lo que oferta la Universidad y lo que necesita los docentes, la importancia de la formación profesional permanente, prácticas bien

\footnotetext{
${ }^{25}$ El termino Movimiento de Renovación Pedagógica (MRP) es un concepto que se define por primera vez en las Jornadas que organizan estas escuelas de verano, muy extendida por toda la geografía española, pero que tienen su principal foco en Cataluña). El primer Congreso estatal de los MRPs se celebra en Barcelona en el mismo año 1981.
} 
planificadas, bien guiadas y bien evaluadas en las diferentes etapas de los estudios y planteamiento de la carrera profesional del magisterio.

De otra parte el MUI, en los famosos acuerdos de Segovia, reunidos por primera vez, en esa ciudad en 1980, y más tarde en 1981 redacta sendos informes respectivamente, contando con la colaboración de las personas que dirigían las Escuelas de Profesorado de EGB, antiguas Escuelas Normales, y la Conferencia episcopal, pero no consiguieron llegar a conclusiones, divididos entre una formación académica o profesional (Benejam Arguimbau, 2002).

En 1980 se formuló la Ley Orgánica por la que se regulan los centros escolares (LOECE), pero se derogará en el 82.

Los movimientos de renovación pedagógica siguen trabajando y durante los cursos 1981 y 82 la Dirección General d’Ensenyament Universitari organizó un seminario de trabajo con alta participación de las siete Escoles de Mestres de Cataluña, para elaborar una propuesta común, pero no alcanzaron consenso.

Llega 1982 y con él un cambio de gobierno y por tanto un cambio en el ministerio que paralizó todo el trabajo realizado, hasta el momento. Los Movimientos de renovación pedagógicos, siguieron debatiendo sin llegar a aunarse en una propuesta. El nuevo gobierno socialista constituye comisiones para desarrollar la LRU, ley de la reforma universitaria, entre otras estaba la conocida como Comisión 15 que debería encargarse del desarrollo de la formación del profesorado, esta comisión estuvo dirigida por José Jimeno Sacristán y consiguió presentar una propuesta global y coherente apoyada en tres puntos clave: a) Garantizar la formación universitaria en una $o$ dos materias $y$ en una $o$ varias complementarias, lo que suponía un ciclo de estudios superiores a tres años, para todos los estudiantes. b) Los futuros estudiantes del magisterio deberían de recibir dos años de formación profesional teórica y práctica que les capacite para hacerse cargo de un grupo de alumnos e integrarse en un equipo de maestros. c) Imprescindible un curso de prácticas guiadas, al finalizar los estudios.

Reivindicaciones importantes, sí, pero que dejaban sin nombre y sin nombrar las especificidades que requería el sistema educativo, si quería educar en igualdad de género.

Pero este último plan tampoco lo aprobó el Consejo de Universidades, y no recibió apoyo del gobierno. Otra desilusión, otro intento fallido... otra vez la formación del profesorado, pieza clave en cualquier renovación pedagógica, se deja sin consensuar... en la política de consenso...en materia de educación, no hay reforma que pueda con tanta historia...Benejam Arguimbau (2002) afirma que con la Comisión 15 termina el último intento de renovación pedagógica del profesorado.

De 1977 a 1982 se considera el periodo de máxima actividad, la educación reclamaba utopía, libertad; los colegios religiosos, libertad de enseñanza, los colegios públicos, calidad. Los movimientos HOAC, JOC, JEC, la editorial ZYX, los sindicatos clandestinos, los partidos de la izquierda, la agrupaciones anarquistas... han sido el caldo donde se han cultivado las ideas y los hombres y mujeres que irrumpen en los movimientos de renovación 
pedagógica... Se han hecho grandes avances, no hay duda, las herramientas para trabajar por la igualdad de género son las mejores con las que hemos contado las mujeres a lo largo de la historia de la educación española. Pero una sociedad no siempre puede estar en lucha- la revista Triunfo cierra en 1982- ni la política dar satisfacción a todo un estado y viene un periodo de relajación social... se profesionaliza la política, las élites de la política cuidan paternalmente de la educación... los MRPs, reciben subvención.... El que se mueva no sale en la foto... El cambio que se avecina es liberal, rentable y no tiene, precisamente, nombre de mujer.

La utopía da paso a lo cotidiano, todo ha de responder a un canon, todo tiene un lado perverso. Todo el argumento apunta a reprimir la diferencia, nuestra esencia.

\section{BIBLIOGRAFÍA}

- Agulló Díaz, Ma del Carmen (1999): “Azul y rosa. Franquismo y educación femenina”. En: Alejandro Mayordomo (coord.): Estudios sobre la política educativa en el franquismo. València: Universitat de València, p. 243-295.

- Ayala, María de los Ángeles (2001): "Emilia Pardo Bazán y la educación femenina”. En: Salina, $\mathrm{n}^{\circ} 15$, pp. 183-190.

- Benejam Arguimbau, Pilar (2002): "Las Escuelas Normales en tiempos de la transición”. En: Historia y Educación, no 21, pp. 81-90.

- Castilla del Pino, Carlos (1971): Cuatro ensayos sobre la mujer. Madrid: Alianza Editorial

- España (1857): “Ley de Instrucción Pública de 9 de septiembre de 1857”, [en línea] Disponible en: http://personal.us.es/alporu/legislacion/ley9set1857_4.htm [12/01/2013].

- España (1970): “Ley 14/1970, de 4 de agosto, General de Educación y Financiamiento de la Reforma Educativa. Publicada. En: Boletín Oficial del Estado, nº 187 de 6 de agosto de 1970, pp. 12525-12546.

- Fernández Soria, Juan Manuel y Agulló Díaz, María del Carmen (1999): “Depuración de maestras en el franquismo”. En: Estudios de Historia contemporánea, 17, pp. 249-270.

- Gago, Sonsoles S.R. (1998): Las primeras maestras. Barcelona: Editora Ariel.

- Groves, Tamar (2011): "El maestro rural como agente de cultura alternativa durante la transición española. El caso de la provincia de Salamanca”. En: Revista de Pedagogía de la Universidad de Salamanca, $\mathrm{n}^{\mathrm{o}} 17$ (ejemplar dedicado a: Participación y colaboración en los procesos de inclusión educativa), pp. 133-143.

- Junta de Andalucía - Unidad de Igualdad y Género (2003): “Jornadas Internacionales, 8,9 y 10 de octubre de 2003: Guía para la evaluación del impacto en función del género”. En: Actas de las Jornadas, [en línea] Disponibles en: http://www.juntadeandalucia.es/institutodelamujer/ugen/sites/default/files/documentos/Modulo _16_transversalidad.pdf [20/02/2013]. 
- La Ley Moyano 1957, [en línea] Disponible en: http://personal.us.es/alporu/historia/ley_moyano.htm [12/01/2013].

- Ministerio de Educación Cultura y Deporte (2004): El Sistema Educativo Español. Madrid: MECD/CIDE, [en línea] Disponible en: http://uom.uib.cat/digitalAssets/202/202199_6.pdf [11/01/2013].

- Moreno Seco, Mónica (ed.) (2005): Manifiestos feministas. Antología de textos del movimiento feminista español (1965-1985). Alicante: Universidad de Alicante.

- Pecellin, Manuel (1987): El Kaussismo en Badajoz: T. Romero de Castilla. Cáceres: Universidad de Extremadura.

- Puleo, Alicia H (1973): Condorcet, De Gouges. De Lambert y otros. La Ilustración olvidada. La polémica de los sexos en el siglo XVIII. Madrid: Anthropos.

- Quintana, Manuel José. (1946): Obras completas. Madrid: Biblioteca de Autores Españoles.

- Richmond, Katheleen (2012): Las mujeres en el fascismo español: La Sección Femenina de la Falange, 1934-1959. Madrid: Alianza - Ensayo.

- Robles Sanjuán, Victoria (2010): "Discursos y estrategias para un proyecto de escuela coeducativa en la transición española. Algunas fuentes para su estudio". En: Cabás: Revista del Centro de Recursos, Interpretación y Estudios en materia educativa (CRIME) de la Consejeria de Educación del Gobierno de Cantabria (España), $\mathrm{n}^{\circ}$ 3. [en línea] Disponibel en: http://revista.muesca.es/index.php/articulos3/145 [18/02/2013].

- Rousseau, Jean. J. (1973): Emile o de la Educación. Barcelona: Fontanella.

- Ruiz Berrio, Julio (1970): Política escolar de España en el siglo XIX. 1808-1833. Madrid: CSIC.

- Sáenz del Castillo, Andrés (1999): "El (o) caso de los movimientos de renovación pedagógica (MRPs)". En: Revista Electrónica Interuniversitaria de formación del profesorado, Vol. 2, $n^{o}$ 1, [en línea] Disponible en: http://www.uva.es/aufop/publica/revelfop/99-v2n1.htm [15/12/2012].

- Subirats, Marina (1994): “Conquistar la igualdad. La coeducación hoy”. En: Revista Iberoamericana de Educación, n 6 (Número dedicado a Género y Educación), pp.49-78.

(1999): "El modelo de educación femenina en la etapa de formación de la escuela moderna". En: V.V.A.A.: Sociedad, cultura y educación. Homenaje a Carlos Lerena. Madrid: Centro de Investigaciones Sociológicas. pp. 209-228.

- Siguan, Miquel (1977): "La psicología en España”. En: Anuario de psicología, no 16, pp. 322.

- Threlfall, Mónica (2009): "El papel transformador del movimiento de mujeres en la transición política española”. En: Carmen Martínez Ten; Purificación Gutiérrez López y Pilar González Ruiz (eds.). El movimiento feminista en España en los años 70. Madrid: Cátedra/Feminismos, pp. 17-52. 